\section{IMPLICATIONS OF INFORMATION SYSTEMS USE ON THE DEVELOPMENT OF WEB 2.0 BASED KNOWLEDGE MANAGEMENT SYSTEM FRAMEWORK}

\author{
Mladen Veinović, Mladen Opačić \\ Singidunum University, Belgrade
}

\begin{abstract}
:
Web 2.0 technologies or as they are also called social technologies have become very popular lately. Social networks like Facebook and LinkedIn have millions of daily users. Wikipedia is the most popular encyclopedia. Blogs of all kinds have become very influential in our everyday lives almost like print media. Although Web 2.0 technologies popularity is great, existing knowledge management system frameworks are usually based on other technologies and principles. Even when they are based on Web 2.0, predominant presumption is that these technologies are completely new. This is normal since substantial portion of those frameworks were developed when these technologies were new. Today situation has changed and average knowledge worker should be familiar with most of these technologies. In this paper we try to quantify popularity that most popular of Web 2.0 systems have, compare their popularity with other business information systems and classify them into three groups by popularity and usefulness.
\end{abstract}

\section{Key words:}

knowledge management,

Web 2.0,

knowledge management system framework,

social media.

\section{INTRODUCTION}

Web 2.0 technologies or as they are also called social technologies have become very popular lately. Social networks like Facebook and LinkedIn have millions of daily users. Wikipedia is the most popular encyclopedia. Blogs of all kinds have become very influential in our everyday lives almost like print media. Although there are many more Web 2.0 technologies these three technologies are thought of as most important in the sense of the organizational use [1]. Web 2.0 technologies are also increasingly taking more and more space in knowledge management practice [2].

Although Web 2.0 technologies popularity is great, existing knowledge management system frameworks are usually based on other technologies and principles. Predominantly Web 1.0 technologies and principles to be exact, but there are also frameworks based on semantic technologies or so called Web 3.0 technologies. Even when frameworks are based on Web 2.0 they tend to view Web 2.0 as something completely new and certainly not as globally popular technologies that everybody is acquainted with.

Web 1.0 [3] was characterized by read-only websites and proprietary technologies. Web 2.0 on the other side is mostly based on free open source technologies and user generated content.
Traditionally [4] one of the most important problems of knowledge management systems has been their ROI (Return on investment). Many of the first knowledge management systems did not live to the expectations [5]. After very large initial investments, sometimes measured in millions of dollars, some of the early knowledge management systems failed to deliver any tangible results. Since it is still very hard to predict the effects of knowledge management system implementations, it is still equally difficult [6] to secure an adequate budget. Web 2.0 technologies solve this problem by being almost free. Initial investment is very small or almost nothing so any return is generally positive. Even when there is a monthly fee, like in some modern cloud solutions, there is always a free trial period. This helps organizations to avoid spending large sums of money for licensed software before even knowing if the solution is right for them. For example most popular enterprise social networking systems such as Yammer, Jive and Chatter are all cloud based solutions and all offer free trial before purchase.

One of the most important qualities of Web 2.0 technologies is their ease of use and intuitiveness. The fact that they are easily used without any formal training is a huge advantage compared to other complicated systems. This also eliminates substantial portion of costs associated with training of employees. That's why it is very important for every knowledge management system framework which is based on Web 2.0 to exploit this. 
Worst case scenario in employee training and organizational learning, from the aspect of amount of training needed, is of course the case of a new employee. It is for this reason that we focus on undergraduate students and their experience with various information systems. This paper tries to answer the question of what implications does the undergraduate student possession of knowledge of various information systems have on Web 2.0 based knowledge management system framework.

\section{LITERATURE REVIEW}

Ever since the first Web 2.0 conference in 2004 when the term has been officially introduced [7] and defined there are a lot of different views on this topic. Some view Web 2.0 as a collection of new technologies, others think of it as a new phase in the evolution of the Internet. Application of Web 2.0 in the enterprise is also called Enterprise 2.0 by some authors [8]. From the Internet that was "read only" we moved into Internet of collaboration and co-creation of contents. The term social web comes from this approach [8]. In scientific literature on Web 2.0 for KM there are generally two approaches. First approach studies Web 2.0 phenomenon as a whole. Second approach focuses on a particular technology.

Approaches that view Web 2.0 as whole generally focus on the creation of a model or a framework. Web 2.0 brings many changes to knowledge management [9] it allows KM to move from document-centric world of Web 1.0 towards people-centric world of Web 2.0. Focus on people encourages virtual communities of practice and a knowledge sharing culture [8] . It empowers people to take part in knowledge creation and sharing. Besides knowledge creation and sharing Web 2.0 principles also help employees to build new relationships based on mutual trust [9]. But all this freedom is not without problems; vandalism, spam and leaking of sensitive information [5] comprise some of the biggest challenges related to the use of Web 2.0 technologies. It is also important [1] to explain the benefits of using Web 2.0 technologies to all employees and put in place incentive mechanisms and guideline policies.

Although research of knowledge management system frameworks and models based on Web 2.0 is relatively new sub-field of knowledge management, there is a substantial amount of different frameworks [1]. Most numerous are frameworks comprised of best practice guidelines in implementation of Web 2.0 technologies. However, none of them takes into account previous experience employees have with Web 2.0 technologies. Predominant approach is that these technologies are completely new to employees when they are introduced. This is normal since substantial portion of those frameworks were built five to ten years ago when these technologies were completely new. Today situation is completely different and average knowledge worker should be familiar with most of these technologies.

Since from the standpoint of cost savings Web 2.0 benefits are quite clear it didn't take much time for knowledge management practitioners and theoreticians to no- tice numerous subtopics within KM that will profit the most from Web 2.0. Those subtopics include application of Web 2.0 concept for personal knowledge management (PKM), small and medium enterprises (SMEs) and recently cloud applications.

Personal knowledge management is the application of knowledge management on personal level. Knowledge management focuses on managing organizational knowledge; personal knowledge management is more about learning, socializing and working efficiently[10] . According to [11] personal knowledge management has grown from many fields including management, personal information management, education, psychology and many more. The term personal knowledge management was first coined by Frand and Hixon in 1999 [12]. They described it as a conceptual framework for organization and integration of information into personal knowledge base. This concept has evolved so that it now includes developing of networks, collaboration, sharing and integrating personal knowledge spaces into group or organizational knowledge spaces [13]. Application of Web 2.0 for personal knowledge management is sometimes also called PKM 2.0[10] . Since individuals generally have to personally finance these systems, price is a very big issue in PKM[14].

Another area where knowledge management system price is important is small and medium enterprises. According to [15] implementation of knowledge management initiatives is crucial since knowledge is a key resource of a SME. In resource theory[16] competitive advantage is attained by resources that are valuable, inimitable, non- substitutable and rare. In that sense advantage gained directly by Web 2.0 technologies will only last until everyone starts using them [3], however organizations that use full potential of Web 2.0 in an innovative fashion will achieve sustainable competitive advantage. Small organizations are much more adaptable and innovative and for them using Web 2.0 offer new opportunities. Traditional knowledge management systems were very expensive to develop and maintain. Cloud computing offers the opportunity for smaller organizations to use these very expensive systems for just a fraction of the price[17]. For large organizations it offers unprecedented scalability and frees them from large investments in hardware and software licenses. However, there are serious problems with trust, security, regulations and availability of cloud services. If organization overcomes these problems it can combine cloud services into a very specialized cloud knowledge management system [15].

The number of different Web 2.0 technologies is so big that some authors[18] doubt that it is possible to count them. Although they are very numerous not all of them are thought to be equally useful to knowledge management. Technologies that are most prevalent in literature [1] include wikis, blogs and social networks.

Wikis are possibly the most popular Web 2.0 technology they are generally used for collaborative content creation and knowledge sharing. Great example of wiki website is Wikipedia, an online encyclopedia that is completely written and maintained by hundreds of thou- 
sands of its users. Term wiki is originally from Hawaiian language and means quick [19][20]. First wiki was created by Ward Cunningham in 1995 and was called WikiWikiWeb. Wiki technology can be best described as a concept of websites maintained by users who have system access [21]. According to [19] wikis are Web 2.0 information systems which can be used for maintenance of knowledge networks, construction of knowledge communities, cooperation in construction of knowledge and knowledge management. Main advantages of wikis are ease of use, mechanisms for preventing vandalism, centralized repository, collaboration between organizations, solving information overload caused by emailing numerous drafts and building a trusting culture [22]. Organizations use wikis for many different purposes, from using Wikipedia and other public wikis through external wikis for interaction with partners and customers to intranet wikis that support group communication and collaboration [23]. According to [24] wikis used in organizations can be used as single-contributor wikis, group or project wikis and company-wide wikis. Enterprise use of wikis is not without problems. Besides usual problems that every information system brings wikis success depends employees willingness to contribute and on number of available employees[25]. Wikipedia has millions of readers and hundreds of thousands of contributors. The ratio of contributors to readers must be much greater in an enterprise wiki in order for it to be successful[25].

The term blog comes from weblog. Blogs are online journals that are regularly updated by its creators [3]. Person that is writing the blog is called blogger. Part of the Internet that is comprised of blogs is often referred to as blogosphere [26]. Blogs are often specialized for one topic. Content of blogs is generally textual but blogs can contain images, audio and video [26]. Biggest difference that blogs have compared to regular websites is the ability of users to comment blog articles [3]. This characteristic of blogs leads to formation of communities around blogs [24].

The term social network was coined by Barnes in 1954 [27]. Since then social networks have been subject of research in many fields of science including, but not limited to organizational studies, geography, psychology, anthropology and computer science. Social networking systems are information systems built for making and maintaining of social networks[28]. These networks can be networks of friends or professional networks [29]. Their main features include user profiles, ability to make privileged contacts and join groups [28].

\section{METHODOLOGY}

We start this research with three goals in mind. First goal is to test for general acceptance of Web 2.0 technologies. Second goal is to see what the relationship between Web 2.0 and other technologies is. Third goal is to see which Web technologies are most popular and to classify the technologies into three groups by level of familiarity and acceptance. In order to achieve these goals we carried out a questionnaire survey. Subjects of the survey were undergraduate students of Faculty for Information and Computing of Singidunum University. Total of $\mathrm{N}=91$ valid questionnaires were received. Out of that number $67(74 \%)$ respondents were male and 24 (26\%) respondents were female. This ratio is normal for an IT faculty. Average age of students was 23.14, median 22 and mode of the sample was 21 . Questionnaire consisted of fifteen questions about information technologies and two about age and gender. Questions were all in the form of "I have used X in the capacity of the ordinary user", where $\mathrm{X}$ is name of the technology. For each question there were three answers "Yes", "No" and "I don't know". Aside from Web 2.0 technologies such as social networks, wikis, blogs, microblogs, instant messaging we also asked respondents about their familiarity with other popular enterprise technologies. Namely, these included email, forums, portals, CRM (Customer relationship management), ERP (Enterprise Resource Planning), DAM (Digital Asset Management), DMS (Document Management System), DAM (Digital Asset Management), LMS (Learning Management Systems), BPM (Business Process Management) and WCMS (Web Content Management System).

\section{RESULTS}

Results of the survey are shown in Table 1. It is obvious that we can classify results into three groups by popularity of technologies in question. First group is used by around $100 \%$ of the respondents. This group is comprised of five technologies email, social network, instant messaging, wikis and forums. Second group is used by close to $50 \%$ of the respondents. This group is comprised of three technologies blogs, micro blogs and web content management systems.
Table 1. Results

\begin{tabular}{|l|r|r|r|r|r|r|}
\hline \multirow{2}{*}{ Technology } & \multicolumn{2}{|c|}{ Yes } & \multicolumn{2}{c|}{ No } & \multicolumn{2}{c|}{ I don't know } \\
\cline { 2 - 7 } & $\boldsymbol{N}$ & \multicolumn{1}{c|}{$\%$} & $\boldsymbol{N}$ & \multicolumn{1}{c|}{$\%$} & \multicolumn{1}{c|}{$\boldsymbol{N}$} & \multicolumn{1}{c|}{$\%$} \\
\hline Email & 91 & $100.00 \%$ & 0 & $0.00 \%$ & 0 & $0.00 \%$ \\
\hline Social network & 85 & $93.41 \%$ & 6 & $6.59 \%$ & 0 & $0.00 \%$ \\
\hline Micro blog & 42 & $46.15 \%$ & 47 & $51.65 \%$ & 2 & $2.20 \%$ \\
\hline Wikis & 91 & $100.00 \%$ & 0 & $0.00 \%$ & 0 & $0.00 \%$ \\
\hline Blog & 44 & $48.35 \%$ & 46 & $50.55 \%$ & 1 & $1.10 \%$ \\
\hline Instant messaging & 85 & $93.41 \%$ & 6 & $6.59 \%$ & 0 & $0.00 \%$ \\
\hline CRM & 8 & $8.79 \%$ & 70 & $76.92 \%$ & 13 & $14.29 \%$ \\
\hline ERP & 10 & $10.99 \%$ & 69 & $75.82 \%$ & 12 & $13.19 \%$ \\
\hline DAM & 5 & $5.49 \%$ & 71 & $78.02 \%$ & 15 & $16.48 \%$ \\
\hline DMS & 17 & $18.68 \%$ & 60 & $65.93 \%$ & 14 & $15.38 \%$ \\
\hline Forum & 82 & $90.11 \%$ & 9 & $9.89 \%$ & 0 & $0.00 \%$ \\
\hline LMS & 24 & $26.37 \%$ & 56 & $61.54 \%$ & 11 & $12.09 \%$ \\
\hline Intranet portal & 8 & $8.79 \%$ & 74 & $81.32 \%$ & 9 & $9.89 \%$ \\
\hline BPM & 6 & $6.59 \%$ & 75 & $82.42 \%$ & 10 & $10.99 \%$ \\
\hline WCMS & 38 & $41.76 \%$ & 49 & $53.85 \%$ & 4 & $4.40 \%$ \\
\hline
\end{tabular}


Third group consists of technologies that are used by very small percentage of the respondents.

Results by gender for male respondents can be observed in Table 2.

Table 2. Results male respondents

\begin{tabular}{|l|r|r|r|r|r|r|}
\hline \multirow{2}{*}{\multicolumn{1}{|c|}{ Technology }} & \multicolumn{2}{|c|}{ Yes } & \multicolumn{2}{c|}{ No } & \multicolumn{2}{c|}{ I don't know } \\
\cline { 2 - 7 } & $\boldsymbol{N}$ & \multicolumn{1}{c|}{$\%$} & $\boldsymbol{N}$ & \multicolumn{1}{c|}{$\%$} & \multicolumn{1}{c|}{$\boldsymbol{N}$} & \multicolumn{1}{c|}{$\%$} \\
\hline Email & 67 & $100.00 \%$ & 0 & $0.00 \%$ & 0 & $0.00 \%$ \\
\hline Social network & 62 & $92.54 \%$ & 5 & $7.46 \%$ & 0 & $0.00 \%$ \\
\hline Micro blog & 32 & $47.76 \%$ & 34 & $50.75 \%$ & 1 & $1.49 \%$ \\
\hline Wikis & 67 & $100.00 \%$ & 0 & $0.00 \%$ & 0 & $0.00 \%$ \\
\hline Blog & 32 & $47.76 \%$ & 34 & $50.75 \%$ & 1 & $1.49 \%$ \\
\hline Instant messaging & 61 & $91.04 \%$ & 6 & $8.96 \%$ & 0 & $0.00 \%$ \\
\hline CRM & 5 & $7.46 \%$ & 52 & $77.61 \%$ & 10 & $14.93 \%$ \\
\hline ERP & 7 & $10.45 \%$ & 51 & $76.12 \%$ & 9 & $13.43 \%$ \\
\hline DAM & 4 & $5.97 \%$ & 53 & $79.10 \%$ & 10 & $14.93 \%$ \\
\hline DMS & 13 & $19.40 \%$ & 44 & $65.67 \%$ & 10 & $14.93 \%$ \\
\hline Forum & 63 & $94.03 \%$ & 4 & $5.97 \%$ & 0 & $0.00 \%$ \\
\hline LMS & 19 & $28.36 \%$ & 41 & $61.19 \%$ & 7 & $10.45 \%$ \\
\hline Intranet portal & 5 & $7.46 \%$ & 57 & $85.07 \%$ & 5 & $7.46 \%$ \\
\hline BPM & 3 & $4.48 \%$ & 59 & $88.06 \%$ & 5 & $7.46 \%$ \\
\hline WCMS & 31 & $46.27 \%$ & 34 & $50.75 \%$ & 2 & $2.99 \%$ \\
\hline
\end{tabular}

It is evident that percentage is very similar. In the first group wikis and email are still at $100 \%$, social networks and instant messaging are down a little and forum is up by four percentage points. In the second group blog and micro blog are nearly the same and WCMS are up by around five percentage points.

Results by gender for female respondents can be observed in Table 3. Percentage is again very similar but there are differences. In the first group wikis, email and instant messaging are at 100\%, social network is at $~ 96 \%$

Table 3. Results female respondents

\begin{tabular}{|l|r|r|r|r|r|r|}
\hline \multirow{2}{*}{\multicolumn{1}{|c|}{ Technology }} & \multicolumn{2}{|c|}{ Yes } & \multicolumn{2}{c|}{ No } & \multicolumn{2}{c|}{ I don't know } \\
\cline { 2 - 7 } & $\boldsymbol{N}$ & \multicolumn{1}{c|}{$\%$} & $\boldsymbol{N}$ & \multicolumn{1}{c|}{$\%$} & $\boldsymbol{N}$ & \multicolumn{1}{c|}{$\%$} \\
\hline Email & 24 & $100.00 \%$ & 0 & $0.00 \%$ & 0 & $0.00 \%$ \\
\hline Social network & 23 & $95.83 \%$ & 1 & $4.17 \%$ & 0 & $0.00 \%$ \\
\hline Micro blog & 10 & $41.67 \%$ & 13 & $54.17 \%$ & 1 & $4.17 \%$ \\
\hline Wikis & 24 & $100.00 \%$ & 0 & $0.00 \%$ & 0 & $0.00 \%$ \\
\hline Blog & 12 & $50.00 \%$ & 12 & $50.00 \%$ & 0 & $0.00 \%$ \\
\hline Instant messaging & 24 & $100.00 \%$ & 0 & $0.00 \%$ & 0 & $0.00 \%$ \\
\hline CRM & 3 & $12.50 \%$ & 18 & $75.00 \%$ & 3 & $12.50 \%$ \\
\hline ERP & 3 & $12.50 \%$ & 18 & $75.00 \%$ & 3 & $12.50 \%$ \\
\hline DAM & 1 & $4.17 \%$ & 18 & $75.00 \%$ & 5 & $20.83 \%$ \\
\hline DMS & 4 & $16.67 \%$ & 16 & $66.67 \%$ & 4 & $16.67 \%$ \\
\hline Forum & 19 & $79.17 \%$ & 5 & $20.83 \%$ & 0 & $0.00 \%$ \\
\hline LMS & 5 & $20.83 \%$ & 15 & $62.50 \%$ & 4 & $16.67 \%$ \\
\hline Intranet portal & 3 & $12.50 \%$ & 17 & $70.83 \%$ & 4 & $16.67 \%$ \\
\hline BPM & 3 & $12.50 \%$ & 16 & $66.67 \%$ & 5 & $20.83 \%$ \\
\hline WCMS & 7 & $29.17 \%$ & 15 & $62.50 \%$ & 2 & $8.33 \%$ \\
\hline
\end{tabular}

As the results clearly show there are three groups of technologies. Email, social network, instant messaging, forums and wikis are by far the most popular with around $100 \%$ acceptance. Blogs, micro blogs and WCMS are still very popular with around $50 \%$ acceptance. Other technologies that we tested are clearly not that familiar to the ordinary respondent of the survey. Taking into account that we surveyed students at an IT faculty and not average student we can conclude that third group of technologies is generally not familiar to ordinary people.

We will now focus on discussing first and second group of technologies one at a time. Email is in the first group of technologies and a technology that is considered de facto standard in business communication. All respondents in the survey indicated that they have used it as ordinary users. This was off course expected. Second of the technologies in the first group were wikis. All respondents in the survey also indicated that they have used wikis which makes wikis as popular as email. Literature review did show that wikis are very popular but we didn't expect it to be as popular as email.

Third of the technologies in the first group are social networks (Fig. 1) with $93.41 \%$ which is also expected after the literature review. Gender differences are almost insignificant with $92.54 \%$ and $95.83 \%$ for male and female respondents respectively.

Fourth of the technologies in the first group, instant messaging (Fig. 2), with $93.41 \%$ is also a little surprising especially when we look into numbers by gender. With $91.04 \%$ for male and $100 \%$ for female respondents instant messaging is a must have in any knowledge management initiative. This is especially true for organizations that are predominantly female.

Fifth and final technology in first group is forum technology (Fig. 3). Depending on authors and definitions of Web 2.0 forums are classified as Web 1.0 or Web 2.0 technologies. A result of $90.11 \%$ is a very big surprise. Some authors do mention forums in their knowledge management frameworks but they are predominantly thought of as something that is old and outdated. Here we have evidence that sample with median of 22 and mode of 21 has used these technologies. Off course one question doesn't tell us much about the quality and the quantity of their experience but certainly qualifies forum as a technology for a knowledge management system framework.

This is even more important for a predominantly male organization since $94.03 \%$ of male

and forum is down to $\sim 79 \%$. In the second group blog is at 
respondents indicated that they have used forum which makes forum more popular than social network with men. Female respondents however are not so fond of forum software but $79.17 \%$ is also significant.

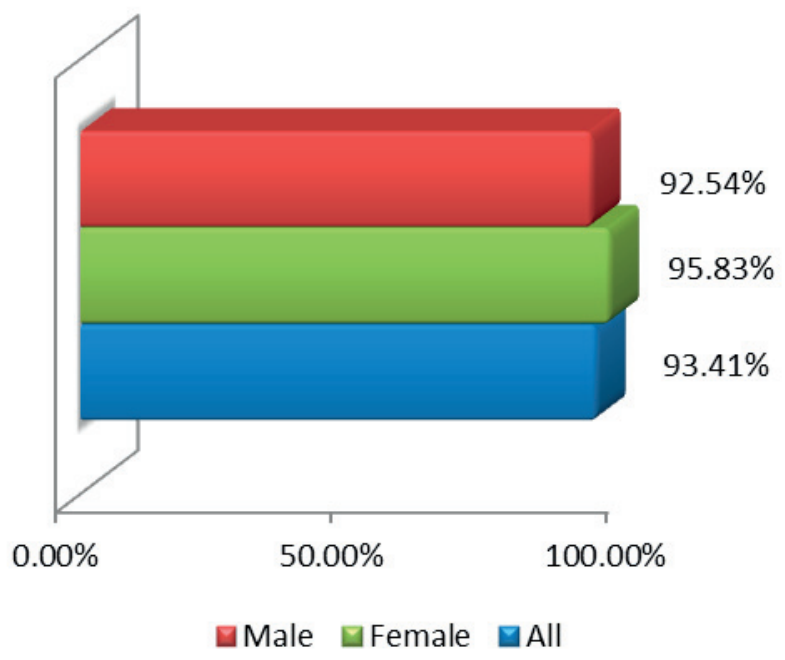

Fig 1. Response "Yes" for social networks

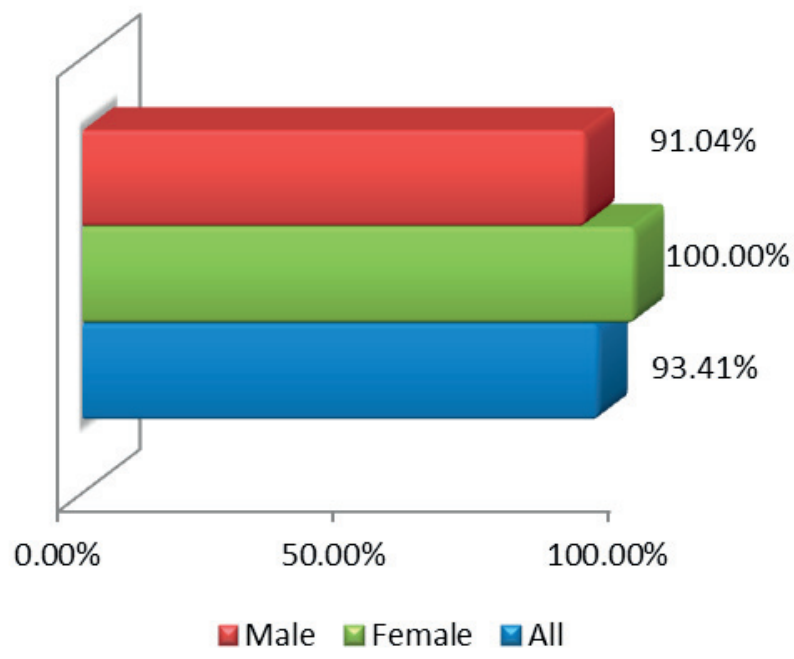

Fig 2. Response "Yes" for instant messaging

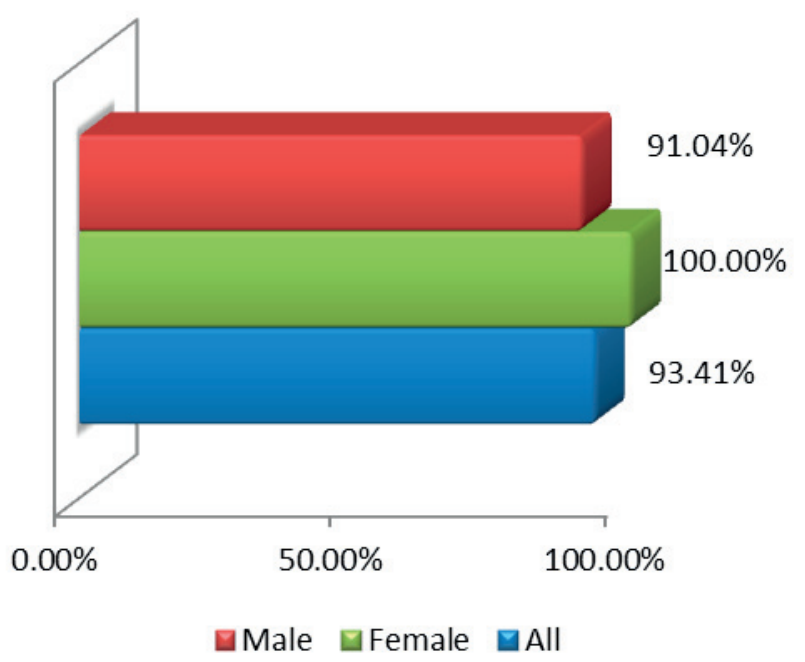

Fig. 3. Response "Yes" for forum
Second group of technologies consists of three technologies that are very similar in nature, as all of them can be used for blogging. Blogs and micro blogs are a very big disappointment while WCMS are a big positive surprise. Judging by the status that blogs have in literature we expected them to be at least as popular as social networks and wikis but this is not the case. However they are still a viable option to be used for knowledge management initiatives.

\section{CONCLUSION}

After everything that we said earlier we can conclude that Web 2.0 technologies are very popular within student population. Any organization using these technologies will have no problem finding and hiring experienced users. Also there will be almost no training costs and organization will have the opportunity to test the system before buying it. This indicates that Web 2.0 technologies are indeed much more affordable solutions then classic information systems. Results have also shown that only a small number of students have experience with classic information systems. This small number indicates that those organizations will have much larger training expenses should they decide to hire new people.

Possibly biggest discovery of this research is how clear cut are these groups of technologies. First group comprising of email, wikis, instant messaging, social networking systems and forums are universally accepted with percentage around $100 \%$. Second group is around $50 \%$ and third is below $25 \%$. This has clear implications on the creation of the knowledge systems.

There is however still much work ahead of us. Although we have established how familiar students are with Web 2.0 technologies there are still many unanswered questions. We still don't know much about quantity and quality of their experience. This will be a natural next for further study. Blogs, microblogs and WCMS are also interesting topic for further study as they are all used for same thing just on different level.

\section{REFERENCES}

[1] G. J. Baxter, T. M. Connolly, "Implementing Web 2.0 tools inorganisations: feasibility of a systematic approach" The Learning Organization, vol. 21, no. 1, pp. 6-25, 2014

[2] M.Levy,"Stairways to heaven: implementing social media in organizations", Journal of Knowledge Management, vol 17, no 5, pp. 741-754, 2013

[3] H. D. Kim, I. Lee, C. K. Lee,"Building Web 2.0 enterprises: A study of small and mediumenterprises in the United States", International Small Business Journal, vol 31, pp.156-174, August, 2011

[4] M. Alavi, D. E. Leidner,"Knowledge Management and Knowledge Management Systems: Conceptual Foundations and Research Issues", MIS Quarterly, vol. 25, pp. 107136, March, 2001

[5] J.P. Allen, "Knowledge-Sharing Successes in Web 2.0 Communities", Technology and Society Magazine, IEEE, vol 29, pp. 58-64, Spring, 2010 
[6] S. H. Janes, K. Patrick, F. Dotsika," Implementing a social intranet in a professional services environment through Web 2.0 technologies", The Learning Organization, vol. 21 no. 1, pp. 26-47, 2014

[7] T. O'Reilly, "What is web 2.0", http://oreilly.com/web2/ archive/what-is-web-20.html acessed 10.03.2014

[8] S. Paroutis, A. A. Saleh," Determinants of knowledge sharing using Web 2.0 technologies", Journal of Knowledge Management, vol. 13 no. 4, pp. 52-63, 2009

[9] M. Sigala, K. Chalkiti, "Investigating the exploitation of web 2.0 for knowledge management in the Greek tourism industry: An utilisation-importance analysis", Computers in Human Behavior, vol 30, pp. 800-812, 2014

[10] R. K.F. Cheong, E.Tsui, “The roles and values of personal knowledge management: an exploratory study”, vol. 40 no. 2, pp. 204-227, 2010

[11] M. Swigon, "Personal knowledge and information management - conception and exemplification", Journal of Information Science, vol 38, pp.832-845, September, 2013

[12] J. Frand, C. Hixon, "Personal Knowledge Management : Who, What, Why,When,Where,How?”,http://www.anderson.ucla.edu/faculty/ jason.frand/researcher/speeches/ PKM.htm accessed 10.03.2014

[13] L. Razmerita, K. Kirchner, F. Sudzina," Personal knowledge management The role of Web 2.0 tools for managing knowledge at individual and organisational levels", Online Information Review, vol 33, no 6, pp.1021-1039, 2009

[14] G. Li, Y. Li,"A study on blog based personal knowledge management", Second International Workshop on Knowledge Discovery and Data Mining WKDD 2009, 23-25 January 2009, Moscow

[15] F. Dotsika, K. Patrick,"Collaborative KM for SMEs:a framework evaluation study", Information Technology \& People Vol. 26 No. 4, pp. 368-382, 2013

[16] J. Barney,"Firm resources and sustained conpetitive advantage", Journal of management, vol 17, no 1, pp. 99-120, 1991

[17] N. Sultan," Knowledge Management in the Age of Cloud Computing and Web 2.0: Experiencing the Power of Disruptive Innovations", IEEE engineering management review, vol. 41, no. 4, fourth quarter, december 2013
[18] H. Man, H. Chen, Y. Wu, Q. Jin," CAPK: A Learning Process Model for Web 2.0 Technology Enhanced Community of Practice", Internet of Things (iThings/CPSCom), 2011 International Conference on and 4th International Conference on Cyber, Physical and Social Computing, pp. 546551, Dalian, October, 2011

[19] F. H. Zaidan, M. P. Bax,"Semantic wikis and the collaborative construction of ontologies: a case study", Journal of Information Systems and Technology Management, vol. 8, no. 3, pp. 539-554, Sept/Dec. 2011

[20] C. Meenan, A. King, C. Toland, M. Daly,P. Nagy,"Use of a Wiki as a Radiology Departmental Knowledge Management System", Journal of Digital Imaging, Vol 23, No 2, pp 142-151, April, 2010

[21] A. J. Hester," A comparative analysis of the usage and infusion of wiki and non-wiki-based knowledge management systems”, Inf Technol Manag, vol 12, pp. 335-355, 2011

[22] T. P. L. Grace," Wikis as a knowledge management tool”, Journal of knowledge management, vol 13, no 4, pp. 64-74, 2009

[23] J. Grudin, E. S. Poole, "Wikis at work: success factors and challenges for sustainability of enterprise wikis", WikiSym '10, July 7-9, 2010, Gdańsk, Poland

[24] E. S. Poole, J. Grudin,"A Taxonomy of Wiki Genres in Enterprise Settings", WikiSym'10, July 7-9, 2010, Gdańsk, Poland

[25] S. Grabner-Krauter, "Web 2.0 Social Networks: The Role of Trust", Journal of Business Ethics, vol 90, pp. 505-522, 2009

[26] M. Opačić, M. Veinović, "Veb 2.0 tehnologije u službi menadzmenta znanja”, Tehnika, vol. 60, no. 4, pp. 746-752. (2013)

[27] K. Musial, P. Kazienko, "Social networks on the Internet", World Wide Web, vol. 16 pp.31-72, 2013

[28] M. Opačić, V. Cvijanović, M. Veinović, "Social networking systems through the lens of knowledge management", EIIC 2013, Slovakia, 2013moj06

[29] J. G. Gerard, „Linking in With LinkedIn: Three Exercises That Enhance Professional Social Networking and Career Building" Journal of Management Education, vol.36, pp. 866-897, 2012. 